\title{
Environmental management accounting and waste management practices: $A$ case of a manufacturing company
}

\author{
S. M. Chaturika Seneviratne ${ }^{*}$, Gayasha Kalpani ${ }^{2}$ \\ Department of Accounting, University of Sri Jayewardenepura, Nugegoda, Sri Lanka ${ }^{1,2}$ \\ chaturka@sjp.ac.lk ${ }^{1 *}$,gayashakalpani@gmail.com ${ }^{2}$
}

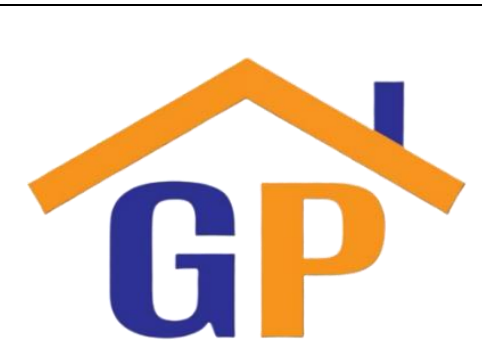

Article History

Received on 15 July 2020

$1^{\text {st }}$ Revision on 22 July 2020

$2^{\text {nd }}$ Revision on 5 August 2020

$3^{\text {rd }}$ Revision on 16 August 2020

Accepted on 23 August 2020

\begin{abstract}
Purpose: This study examines how Environmental Management Accounting practices are related to waste management practices and how the organization in the case study is influenced in adopting the waste management practices
\end{abstract}

Research methodology: The case study method was used in examining the applicability of Environmental Management Accounting to waste management in one large manufacturing company. Interviews, observations and archival documents were used as data collection methods.

Results: The study observed that the company had reinvigorated environmental management and waste management practices due to the influence of the major stakeholders. These motivations can be categorized into three main pillars including coercive, mimetic, and normative isomorphisms.

Limitations: As the research is directed towards the selection of in-depth inquiry of specific settings infused with culture, values, beliefs, stories, language, perception, politics and ideology, it might cause to diminish the researcher's analytical objectivity and independence of the research.

Contribution: Policies, practices and motivations promote the future development of environmental management accounting and waste management practices in the Sri Lankan context.

Keywords: Environmental management accounting practices, Institutional theory, Manufacturing company, Waste management

How to cite: Seneviratne, S. M. C., \& Kalpani, G. (2020). Environmental management accounting and waste management practices: A case of a manufacturing company. Annals of Management and Organization Research, 2(2), 97-112.

\section{Introduction}

There are numerous reasons to consider the environment and waste management practices in the present circumstances. Public awareness of the environment has emerged because of the increasing natural disasters and everyone believes that human beings mainly make the cause for those disasters. These incidents have resulted in the growth of protecting the environment from human activities. It has led the organisations to adopt safer environmental practices. Countries all over the world, especially developing countries, have faced the challenge of increasing waste in urban areas. This problem has created a major issue in developing countries like Sri Lanka as they do not have appropriate space for disposal of waste or developed technology to dispose of the wastage properly. This scenario is mainly created because of the unawareness of the importance of disposal systems in the companies and households in developing countries.

A new trend to protect the environment and natural resources is emerging in developing countries in the present circumstances (Gunarathne, \& Lee, 2014). The governing bodies of most countries work toward driving companies to focus on the environment rather than purely on the company's financial 
successes. As a result, environmental management and waste management practices have emerged as effective management approaches to measure corporate performances (Watchaneeporn, 2010).

In recent years, due to the growing population and the increasing number of companies in Sri Lanka, the disposal level of waste has increased rapidly. However, due to the low demand for proper waste disposal systems, unawareness of waste management and the importance of the Environmental Accounting information to decision making, waste management has become a major issue in recent years in the Sri Lankan context. In Sri Lankan context, the issue of waste disposal has been increased and it has become a threat to human life. As per the estimation of Central Environmental Authority of Sri Lanka, daily generation of solid waste has increased to 6,500 to 7,500 tones. The incidents like the collapse of the Meethotamulla dumping site have recently created awareness of waste management and disposal systems in the local context. As per the Gazette of the Democratic Socialist Republic of Sri Lanka to National Environmental Act No. 47 of 1980, "No person shall, discharge, deposit or emit waste into the environment or carry on any prescribed activity which causes or are likely to cause pollution or noise pollution."

According to the previous studies conducted on waste management and EMA, those have not provided much concern on solid waste management and EMA in the manufacturing sector. Though the significance of environmental issues has emerged, this field is less studied. (Qian and Burritt, 2007). Most of the EMA studies have focused on developing countries, while only a few studies are available on the practices of the developed countries. (Gunarathne and Lee, 2015). As per Gunarathne (2015), the development stages of EMA have not been empirically investigated in relation to Sri Lankan practice. Hence, significant gaps can be seen in Waste Management activities to EMA in most of the manufacturing companies in Sri Lanka.

In the Sri Lankan context, research regarding Waste Management and EMA practices is very limited. Since there is pressure from the government, environmental authorities and consulting organisations, environmental management accounting in the hotel sector have emerged. Since hotels in Sri Lanka have to reinvigorate environmental accounting practices are urgent. Accordingly, the study has been conducted to identify the EMA practices and Waste Management in the hotel sector in the emerging South Asian developing countries. As a result, the study's findings are useful to the service sector organisations to develop and sustain the holistic approach for EMA (Gunarathne and Lee, 2013). Even though waste management is the major issue encountered by society, empirical research in the selected field is limited. Therefore, this paper investigates Environmental Management Accounting to waste management practices in a leading Public limited company in Sri Lanka.

The current study examines the Environmental management accounting practices in $\mathrm{ABC}$ Ceramics PLC, which is the leading tile manufacturer in Sri Lanka. As a leading tile manufacturer, ABC Ceramics PLC can play a major role in developing a system to manage the waste in the country, and take the impact on the environment to the accounting of the company since the company is using natural resources as their main ingredients, such as clay, feldspar, quartz, sand and water. Moreover, the production waste of the company has polluted air, water, hazardous waste and damaged items. The company has a direct impact on the environment. Due to the high impact on the environment from the company, ABC Ceramics PLC has engaged in managing waste and EMA practices. As per the strategy statement, under the principle of integrating sustainability principles, the company started to engage in waste management.

Even though many research findings have considered waste management and Environmental Management Accounting, they were unable to execute their research studies regarding the waste management and EMA in the Public manufacturing Company viewing through the institutional theory. Therefore, the motivation of the study is to investigate the waste management to environmental accounting practices in ABC Ceramics PLC through in-depth single case study approach. Therefore, this study focuses on "How EMA is applicable to the waste Management in the ABC Ceramics PLC". Based on this, the research intends to achieve the following research objectives concerning $\mathrm{ABC}$ Ceramics PLC. 
1) To examine the current waste management and environmental accounting practices concerning company waste?

2) To investigate how the waste Management practices are implemented under EMA in an ABC Ceramics PLC?

3) To explore how ABC Ceramics PLC is influenced in adopting waste management and Environmental Management Accounting practices?

As a leading manufacturer in the country, ABC Ceramics PLC is selected as a case study that plays a major role in developing a system to manage the waste in the country and take the impact on the environment accounting of the company. As per the Sri Lankan context, waste management and engaging in environmental accounting is a duty of the leading companies in Sri Lanka. Even though the responsibility to waste management is having the generator of the waste, the leading companies in Sri Lanka have the responsibility to adopt the relevant management systems and adopt Environmental Accounting practices as they can be moral to the others.

Insights drawn from Institutional Theory are used to understand the motivations to adopt waste management practices. The theory explains how organisations become similar in society according to the various processes and procedures $($ Scott, 1994). The institutional theory considers the organization as a social actor. Regulatory pressures, Community expectations, Cognitive pressures are some pressures for the companies to become similar in the social context. The institutional theory explains the social systems of the organisations broadly (DiMaggio \& Powell, 1983). It explores different mechanisms of socially accepted behavior in institutionalized organisations. As an example, there can be coercive pressure from powerful stakeholders such as government authorities. Further, the organisation can influence mimetic pressure from the norms and practices to adopt waste management and EMA practices - coercive isomorphism results from formal and informal pressures such as government legislation and standards influenced by other institutions. Coercive pressure provides a force to the organization to comply with rules, schemes, and inferential sets (Qian \& Burritt 2009). This pressure instrumentality motivates the organisations to respond to formal and informal pressures implemented by powerful authorities in the organization's external environment. (DiMaggio and Powell 1983, p. 150). Hence, the above-mentioned pressures are considered as forces that might influence or invite to join in collusion. As per Wei Qian and Burritt, compliance with the rules, mandates and standards are helpful to survive and for the company's growth. Accordingly, if a company fails to comply with them, it can result from losses to the company, damage the image, and loss the license to operate as a company.

As per Scott (1995), Mimetic isomorphism emphasises internal figurative representations of the world as mediating between the external world and the individual entity. (Scott 1995, p. 40). If there are well-accepted community actions in the organizational environment, member organisations tend to accept that behaviour to be similar. (Scott 1995, p. 40). According to Wei Qian, simply mimetic behaviour is "The way we do things around here." It is simply the process of "Imitation." The mimetic process generates from social behaviour and from relationships. Since that the pattern of collaboration between entities has become specified by shared systems. These systems have established the limitations of each set of companies. (Scott 1995, p. 40). If the organization has any doubt, the organization prefers to select practices or structures in another successful or legitimate organization. (DiMaggio and Powell 1983). When an adequate number of organisations in one field adopting similar practices, those practices become taken for granted and institutionalised. Ultimately, other performers in the field may follow the practices without questioning.

Above regulatory pillar and Mimetic Pillar can be easily understood and interpretable. However, the Normative pillar is implicit and less identifiable. Normative isomorphism is primarily supported by norms and values models that can be diffused through various organisations such as industry trade associations and consulting firms. These norms and models are "morally governed" and adopted by social players. (Scott, 1995, p. 40). Through the normative process, generally expected or accepted organizational composition and actions can be like rules. Hiring employees from the same industry, 
common promotion practices and common skill-level requirements for relevant job roles can result in normative isomorphism (Gunarathne \& Lee, 2014).

One of the main elements of the EMA is Waste Management. If the company cannot manage the waste generated by the company, it will create a negative impact on the company and the environment. Therefore, managing the waste is essential to the company. It will lead to a better environment for society and to build a good image for the company. Every organization in society tends to become similar in the society according to the various processes and practices. In today's context, there is a huge concern about the environment by society. As per the Institutional theory, this trend has made a platform for applying waste management and EMA practices. Therefore, studies regarding waste management and EMA add value to society. It is important to apply the findings of the research studies in the practical environment. As a result, the need for EMA recording has emerged; hence, Environmental Management Accounting has been established.

Since there is a lack of studies that focused on the effect of waste management on Environmental Management Accounting, this study helps understand the impact of waste management on EMA based on the large manufacturing company ABC Ceramics PLC. When emphasizing the practical significance of waste management to EMA at the company, it is important to be aware of the existing usage of EMA to waste management in the company context. According to previous studies, there are various ways to manage waste in manufacturing companies. However, when implementing those techniques by the company, they may undergo several concerns. Therefore, it has created a huge challenge to the policymakers of the company and for the environment to develop a sustainable way for EMA and Waste Management, which is for the betterment of the company's performance and image. The study findings could be used by the other companies in the same industry or the companies that depend heavily on environmental resources. Under the prevailing laws and regulations of the country, the company must have a proper method to dispose of the waste generated by the company and to meet that requirement, and the company needs human resources, capital, funds, equipment and utensils. However, as it finally affects the company's profit, it is significant to investigate the linkages between waste management and EMA practices of a company whose production considerably adds waste to the environment.

\section{Literature review}

Today, the whole society searches for solutions concerning waste management and environmental protection. As a result, on the one hand, organisations must be concerned about the environment, and some companies make it a competitive advantage to the company. On the other hand, companies are being able to manage their cost on waste disposal activities. This research emphasizes on how waste management practices are adopted by the case organisation and how it relates to EMA practices of the company. This section provides the literature that discusses waste management practices, EMA practices and the motivations to use EMA from different theoretical perspectives in diverse geographical locations and industries.

EMA can be considered a tool for the companies' decision-making that provides required data for corporate environmental management. The diverse information obtained from the EMA can be used for many different practices and report preparation of well-established organisations. While some companies focus on their EMA activities in a narrow range which includes only the cost and benefits gained from EMA practices, others may consider the broader view, which includes both monetary and non-monetary value of EMA. However, prior studies indicate that the application of EMA leads to cost savings, reduction of environmental and social risks, improvement of quality performance and the enhancement of competitive advantage (Watchaneeporn, 2010).

There is no proper, well-accepted definition for the term Environmental Management Accounting. It can be used as a tool for decision-making within the entity. In the practical world, EMA implementation can be considered a range from simple methods to more integrated practices. This function involves identification, collection, analysis of data and using the analysed information for the decision-making of the Managers (Gunarathne and Lee, 2013). 
EMA includes accounting for energy, bio-diversity accounting, carbon accounting, capital budgeting for environmental resources, material accounting, environmental impact accounting etc. (Bennett \& James 1997). As the accounting practices and the influences on the accounting practices are not stable by nature, new EMA practices are being developed day by day. (Gunarathne et al. 2014).

Since environmental issues are arising due to humans' influences on the environment, the emergence of the EMA is very important and has affected managerial decision-making. Even though the EMA is practiced for those reasons, context entities are getting more benefits by practicing them. According to IFAC 2005, the benefits can be divided into three parts. Those are compliance efficiency, ecoefficiency and strategic positioning.

By compliance with the regulations on the environment implemented by the governing entities of a country and by following the self-code of conduct, the company facilitates compliance efficiency. To achieve the eco-efficiency reduction of cost and more efficient use of the environmental resources are very important aspects. The term eco-efficiency must link to Shareholders of the entity and to the business performance. (Gunarathne \& Alahakoon, 2016) When directing the company's strategic direction, EMA is considered a main part of the decision-making. In most cases, companies are using the term EMA in their marketing strategy to attract environment-friendly investors, customers, and suppliers. (Gunarathne \& Alahakoon, 2016).

According to Hwang \& Yeo (2010), waste management can be defined as a system of collecting, transporting, storing, treating, recovering, and disposing of waste to achieve an acceptable level of environmental quality and sustainable development. The European Environment Information and Observation Network (EIONET) has identified the importance of planning waste management and achieving waste management objectives with considering the impact on human health.

El-Haggar (2007) has developed a framework for the guidance of waste management. It is a systematic way to manage waste effectively and efficiently within the organization and there are five steps of the structure. Those are, Reduce, Reuse, Recycle, Recover and Disposal. Waste reduction means reducing the total generated waste from the organizational activities. It is the most preferred and successful way of waste management since through that method, the impact to the environment from the waste can be eliminated. If the organization can reduce the waste at the source, it is a positive impact on the environment and also on society. Reuse and recycle are very close definitions because reuse means materials and objects diverted from waste putting back into use again. Recycling is a process of producing new products from waste materials. While Recycle is a broader process that includes reuse, reprocessing \& remanufacturing, Recover means using many items from waste streams for further usage several times. Disposal stands for managing all the disposal items in the most responsible way to the environment. (Qian \& Burritt 2009). To get the maximum benefit from the waste management to the company and provide benefits to the environment from the waste management, many of the entities have introduced various methods to their waste programme designs.

According to El-Hagger (2007), if a corporation properly follows this framework to manage the waste, it can gain various benefits. Managing waste has positive impacts on the organisations in the present scenario. Well created waste management system will provide economic benefits to the company by reducing the cost of production. Besides the economic benefits, the company can also gain various positive aspects (Hwang \& Yeo, 2010). including, Profit maximization through cost saving, Minimise waste disposal to landfills, Better control of resources to minimise waste, Productivity and quality improvement and Image improvement.

Reduction, reuse, and recycling of waste can generate favourable outcomes for the company. One of the main benefits is cost-saving and profit maximization. Unnecessary purchases of the company can be reduced or eliminated by substituting reused, or recycled items were the reduction of cost to new purchases. In addition to that, generating less waste from the entity results in a reduction in disposal costs. Ultimately, the cost-saving through these activities, in turns, maximises the profit. 
Minimising the waste sent to disposal can lead to less demand for the landfills and reduce the other negative effects such as pollution, noise, and emission. Further, the image of the company can be increased by managing the waste. If a company implements waste management as a company policy, it allows companies to enhance their public image. As an "Environmentally Friendly company", the company can increase the impression on clients. In addition to that, waste management involves planning and controlling the resources committed to projects for controlling the amount of waste generated. Furthermore, better control of organization resources can be achieved through the reduction of waste. Productivity of the process can be increased by avoiding delays in reordering and repurchasing materials and other inputs. Via selecting material in good conditions and durability, significant waste generation can be reduced to a certain level.

Gunarathne \& Lee (2014) suggested that institutional theory can explain the motivations to adopt EMA into practice in the accounting systems within the organization. According to their studies organisations have created a platform to capture the environmental cost and maintain EMA within the organization due to mimetic isomorphism. As per Wei Qian, 2009 there is a strong, unconfirmed presumption that EMA is a necessary tool and foundation for management decision making. Hence, the institutional theory describes how the company has been institutionalized within the society and how the organization becomes similar based on coercive, normative, and mimetic pressures.

Coercive isomorphism results from formal and informal pressures such as government legislations and standards influenced by other institutions. Coercive pressure provides a force to the organization to compliance with rules, schemes, and inferential sets. (Wei Qian and Roger Burritt. 2009). As per Scott in 1995, Mimetic isomorphism emphasises internal figurative representations of the world as mediating between the external world and the individual entity. (Scott 1995, p. 40). If there are wellaccepted community actions in the organizational environment, member organisations tend to accept that behaviour to be similar. (Scott 1995, p. 40). According to Wei Qian, simply mimetic behaviour is "The way we do things around here." It is simply the process of "Imitation."

Normative isomorphism is primarily supported by the norms and values models that can be diffused through various organisations such as industry trade associations and consulting firms. These norms and models are "morally governed" and adopted by social players. (Scott 1995, p. 40). Through the normative process, generally expected or accepted organizational composition and actions can be like rules; for instance, hiring employees from the same industry, common promotion practices and common skill-level requirements for relevant job roles can result in normative isomorphism. (Gunarathne, N \& Lee, KH 2014).

Environment Management Accounting is a new theme for Sri Lankan organisations. To give the respondence to the environment, any organization must change their traditional way of disposal of waste and consider waste management in decision making. Australian National Strategy has recognized the importance of the EMA for waste management on Ecological Sustainable Development (NSESD) (Australian Ecologically Sustainable Development Steering Committee, 1992). They have encouraged the companies to adopt pricing and charging structures that concern the economic and environmental cost of waste disposal. As per Wei Qian (2002), an effective waste management system needs reliable and timely information to identify the efficiency of environmental and waste prevention programs. Thus, the research conducted in the given area would be able to identify the various frameworks and approaches to incorporate the information in relation to EMA into waste management.

\section{Research methodology}

This study collects data about current waste management practices related to the company's environmental management accounting practices. This research is found upon qualitative research methodology and deployed a single case study method because the objective of the study is to conduct an in-depth examination of waste management practices of ABC company. The case study method is a kind of empirical inquiry that investigates a phenomenon within its real-life context. Case studies 
have emerged as a very important qualitative approach in management research disciplines, and this method gives the approach to study and analyze the practice in-depth in the company. The case study method can be identified as the preferable method in the current study because of the nature of the research question, the ability to collect data from multiple sources, and the need to focus on the contemporary real-life phenomenon in the study.

To collect data, the researchers have visited the Head Office of ABC Ceramics PLC and two leading factories in their factory list, situated in Location 1 and Location 2. These factories produced glazed floor and wall tiles in porcelain and ceramic categories. All the products are manufactured for the "ABC" brand. These factories generally use updated and upgraded technology, and therefore they have highly automated production systems and low employee contribution. During the factory visit to these two research sites, researchers were able to collect data from primary sources and secondary sources. The primary data was collected by conducting semi-structured interviews with the Accountant, Head of the production area, Storekeeper and several workers in the factory. The first stage of the interviews was conducted at the factory premises and the snowballing method was used for these interviews. Firstly the interview was conducted with the Accountant of the factory. Then the Accountant introduced the Head of Production to get more details and thereafter the interview with Stokeeper was done who was introduced by Head of Production. Then the Storekeeper nominated Workers of the factory to do several other interviews. All the interviews that were carried out can be categorized as in-depth in nature and semi-structured. The questions raised from the interviews were mostly open-ended and logical and asked questions depending on the way of response.

During the second stage of the interviews, it was able to contact the Accountant, Assistant Accountant, and the Storekeeper of the Location 1 factory and the Head of the Production of the Location 2 Factory for data triangulation. This interview process and the factory visit helped gain and verify the information concerning waste management and environmental management accounting of the company. Prior to visiting the factory, researchers searched and analyzed the website and other documents such as Annual reports and articles on newspapers and magazines available on the internet. The Accountant of the factory was informed about the nature and the objective of the study over the telephone. Thereafter, the interview guide was sent to him to get an overall understanding of the case study. Subsequently, the researchers visited the factory to conduct an initial interview with the Accountant regarding the EMA practices. Having a background understanding regarding the practices of the company, then the researchers visited the factory with Assistant Accountant.

It was able to visit various locations at the factory such as material stores, production area, tile cutting area, tile storing area, recycling plants, public areas, restaurant, and office area. The Assistant Accountant explained the functions and the practices taking place in various locations. During the visit, researchers were able to interview the Head of the production, Storekeeper, workers, and operators. After the factory visit, there was a chance to interview the factory's Accountant regarding the development stages of the EMA \& waste management in the factories. During the factory visit, it was able to notice various locations, including biomass plant, sewerage treatment plant, compost bins, organic farm, and water recycling plant. After visiting two factories, the layouts, functions, and operations were similar in both factories.

For the study, an on-site observation method was used. It was helpful to get a deeper understanding of the EMA activities and waste management practices implemented in reality. During the factory visits, it was able to observe the entire production process and the storing process. Further researchers were able to clarify further matters regarding the company's processes, waste management practices, and EMA practices.

The details were observed from the factories' internal documents, such as a green book, daily and monthly material, and energy record books. Further, the publicly available data on websites, newspaper articles, and magazines were used. Furthermore, through phone calls, the researchers were able to get clarification on further information. During the observations, there were limitations on data accessibility and the limitations for the publicity of the internal information. When collecting the data, 
there can be a point of saturation, and triangulation can be carried out to improve the accuracy of the data collection. In this study, triangulation was carried out via personally collecting data from two factories through observing, interviewing the number of responsible people, and collecting data through secondary sources.

As a leading company that mainly manufactures tiles and associated products, ABC Ceramics PLC directly impacts the environment. The company uses natural resources as its main ingredients. ABC mostly uses the latest technology such as clay, feldspar, quartz, sand and water, and to get a quality, different shaped and sized tile. The production waste of the company has polluted air, Polluted water, hazardous waste and damaged items. During the last financial year (2018/2019), the total disposed of solid waste is 16,108 MT. 687 Mn litres of Polluted water has emerged through the production process.

Due to the high impact on the environment, $\mathrm{ABC}$ Ceramics PLC has engaged in managing waste and EMA practices. As per the strategy statement of the ABC Ceramics PLC, under the principle of integrating sustainability principles, the company started to engage in waste management. In the $2020 / 2021$ financial year, the company management planned to reduce the waste by $40 \%$ from the last year's solid waste disposal. Further, they plan to ensure the safeties of the disposal system of hazardous waste. The management of the company has identified climate change as the risk indicator to the company. If there is climate change, the company cannot find its raw materials properly. To mitigate that risk, they are engaging in waste management for the betterment of the company, human well-being, and the betterment of the environment.

As the main data collection method was to interview, researchers needed to organize the collected data. Content analysis is used to further the analysis of collected data. Data analysis is done to examine existing waste management and accounting practices to EMA, Methods implemented at the company and how those practices are used under EMA. Data Analysis was used to understand the motivations to practice the EMA and waste management practices.

\section{Results and discussions}

\section{Waste generation and composition of waste}

The main purpose of this section is to present the findings of the study. After that, these findings are discussed under the research objectives. Accordingly, this section is divided into three sub-parts based on the objectives of the study. The central objective of the study is to identify "How EMA practices are applicable to the waste management in ABC Ceramics PLC and the motivational factors of adopting such waste management practices in ABC Ceramics PLC."

As per the above-mentioned objectives of the study, under the first objective, researchers have explored waste management practices related to the company's EMA practices. Solid waste, Organic waste, Sludge waste, and Wastewater are the types of waste generated from the manufacturing process. For these all types of waste, the management system is implemented in all the factories. Furthermore, according to the second objective, the company accounts for materials, energy, water, and garbage under their environmental management accounting practices and such accounting information is used for the decision-making process. Concerning the third objective of the study, the data were collected on underlying motivations to adopt these practices under the institutional theory. Motivations from the major stakeholders and the new trends of the organizational environment have created the platform to introduce these practices in this group of companies. Further, past literature related to the waste management and EMA practices and literature relevant to motivations for the company's existing practices were used for the analysis.

\section{Waste generation and composition of waste}

Waste can be generated through various sources and the source of waste generation is more important when implementing a waste management system. Recent research has emphasized the importance of identifying the generator of the waste for a sustainable waste management system. (Wei Qian and Roger Burritt. 2009). As waste generation is one of the important parts of the study, the researchers have used direct \& indirect interviews to gather information regarding waste generation. The 
interviewers confirmed that the existence of multiple sources of waste generation. The Location 1 Factory Accountant commented:

The factory's waste is generated through many sources and at the different stages of the production process. As we are producing several categories of products, we consider the waste with that products. Normally, in this factory, we are producing tiles mainly. As you know, we have tiles, sanitary ware, packaging and other bathroom equipment. So, as a group of companies, we recognise the waste generation according to the above-mentioned product categories according to the policies within the group. In the year-end annual reports, we allocate separate pages to disclose the waste based on product categories.

During the interview with the Assistant Accountant at the Location 2 factory, he commented that a major part of the waste had been generated from the production of tiles. As per his opinion, considerable weight from the waste is created from paper waste, squaring waste, food waste and organic waste. Further, he stated that due to the increase of production compared with the last year, the tile waste from the factory has increased. The latest Annual report of ABC Ceramics PLC (2019/20 ) was evident that the company is using the above-mentioned categorization for the reporting purpose. Accordingly, these explanations and support documents prove that it is considering the source of the generated waste and the composition of generated waste for their reporting purpose as a company.

\section{Existing waste management practices}

Waste management practices of the company can be categorized into five steps. Those are Reduce, Reuse, Recycle, Recover and Disposal (El-Haggar, 2007) . Since the company has well-established waste management practices, the factories can see the above steps. As per the Head of the production of Location 2 factory, the waste management system can be divided into four categories: Reduce, Reuse, Recycle, Recover, and Disposal.

Reduce means reducing the total generated waste from the organisational activities. It is the most preferred and successful way of waste management since through that method, impact to the environment from the waste can be eliminated (El-Haggar , 2007). The company has implemented several methods to minimise production wastage. During the interview, the Head of Production of Location 2 factory commented:

Via selecting material in good conditions and durability, significant waste generation can be reduced to a certain level. For that strategy, we use our own clay mines and selective suppliers to get the materials for the production. Also, we focused on several TPM initiatives, Solid waste separation systems, Strict monitoring systems to reduce wastage.

These explanations are supported by the interview held at the Location 1 factory as well. Accordingly, the Assistant Accountant of the factory stated that the separate officer tests the quality of inputs and the production process. Further, he noted that the production process is highly automated and therefore, the wastage is reduced. Another category is named reuse, which is explained as materials and objects diverted from waste putting back into use again (El-Haggar, 2007). The company has established a waste air grabbing system \& through that machine, the silica sand is collected and used for production again. Further, the company is reusing minerals, paper, organic waste generated. The Head of the production at Location 2 factory mentioned:

In the tile manufacturing sector of the company, $99 \%$ of the minerals used were recycled and reused. Other wastes of the company such as organic waste, paper waste and waste materials are reusing in the production process and some parts are selling to third parties. For those third parties, our waste is an input for their production. Ultimately the waste is reused at another production process.

These explanations are supported during the factory visit. At the factory visit of Location 2, it was observed that the air grabbing system and dust suction plant collects the silica sand dust and provides it for the production process again. Further, as per the records, the company has reused 11,330MT of wastage during the period of 2019/20. The third category is called Recycle. Recycle is the process of 
producing new products from waste materials. Recycling is a broader process that includes reuse, reprocessing \& remanufacturing. (Qian \& Burritt 2009). In the factory, the main recycle wastage item is Wastewater. The Production head of Location 2 factory noted:

In the tile manufacturing sector of the company, $99 \%$ of the minerals used were recycled and reused. The main recycling item is water. Inside the factory, we have a water recycling plant. After recycling the water, it is disposed of safely through effluent treatment plants. The quality of the water is tested prior to discharge. During the 2019/20 period, we were able to recycle about $138 \mathrm{Mn}$ liters of water.

The Assistant Accountant of Location 1 factory commented: "During the last financial period (2019/20), the amount of Wastewater is $196 \mathrm{Mn}$ in liters. From that, we have recycled $121 \mathrm{Mn}$ liters through our effluent treatment plants." Further, these explanations were supported at the factory visits. During the visits, we observed the water recycling system and the way of testing the recycled water before discharging. The figures which were extracted from the 2019/20 annual report have supported these descriptions.

Recover means waste should be used for many items from waste streams for further usage. Disposal stands for managing all the disposal items in the most responsible way to the environment. (Qian \& Burritt 2009). Further, during the factory visit of Location 2, it was able to notice the waste heat recovery system. The waste heat recovery plant is installed in the Location 2 factory and is planning to install in other factories as well. The Accountant of the Location 2 factory commented:

As a highly automated production factory, we are using $70 \mathrm{Mn}-\mathrm{kWh}$ of energy within the group. Our board of directors had a target to save energy. As a result, in the Location 2 factory, we introduced a waste heat recovery plant in September 2019. Furthermore, the board expects to introduce these systems to the other tile factories as well. Through this system, the factory was able to save $321,261 \mathrm{~kg}$ of LPG and 253,773Kwh during 2019/20.

The Assistant Accountant of the Location 1 factory mentioned the other category called disposal. The groups of the companies maintain strict environmental compliance \& ensure the safe disposal of solid waste with segregation.

Mainly, there are three types of items that the company disposes. Those are Wastewater, solid waste, and other waste. These waste disposal methods are complying with the rules $\&$ regulations of the Central Environmental Authority (CEA). Solid waste is disposed of after the segregation. Sludge waste is given to cement manufacturing factories. Wastewater is disposed after the recycling.

The worker at the waste disposal unit commented, "Paper waste, organic waste and some waste materials are selling to third parties. Food waste from the canteens is using as animal feed'. Further, the information regarding the disposal of solid waste and Wastewater can be confirmed using below reports of the company.

Recover is interpreted as the waste heat recovery plant is installed in the Location 2 factory \& planning to install in other factories as well. Further, during the factory visit of Location 2, the waste heat recovery system was observed. The Accountant of the Location 2 factory commented:

As a highly automated production factory, we are using $70 \mathrm{Mn}-\mathrm{kWh}$ of energy within the group. Our board of directors had a target to save energy. As a result, in the Location 2 factory, we introduced a waste heat recovery plant in September 2019. And the board expects to introduce these systems to the other tile factories as well. Through this system, the factory was able to save $321,261 \mathrm{~kg}$ of LPG and $253,773 \mathrm{Kwh}$ during the period of 2019/20.

\section{Waste management practices under EMA}

Through the interviews done, it was found that the applicability of the waste management practices and how those practices link with EMA practices of the company. When it considers about the EMA practices of the company, it follows EMA practices in several areas of waste management. Those 
areas are energy, material, water, and garbage. This section provides the details on how the company uses practices under those three areas.

\section{Accounting for energy}

As per Gunarathne (2015), in every organization in Sri Lanka, irrespective of the size, there is a trending concern on energy management and the associated practices. As a highly automated manufacturing company, ABC Ceramics PLC's energy power consumption such as electricity, fuel, gas, and kerosene oil is very high. The company maintains the records on the energy consumption monthly and based on that. They can compute the energy intensity ratio. Then the company's management can have an idea of the energy consumption at the different periods. Further, they can make decisions on the efficient energy consumption practices and the company has disclosed their energy consumption based on their sectors in the Annual report.

As per the explanations of the Head of production at Location 2 factory, in the case of an electricity failure, the company is using kerosene oil as an energy source for the production process to continue the production using generators. When it considers the cost of using kerosene oil, it is very high. The Assistant Accountant of the Location 1 factory commented:

Since we are using a separate recording system for energy consumption, we can identify the actual energy consumption monthly vise. Our energy intensity ratios present that the usage of energy is increasing and decreasing based on our demand. But with the help of various energy-saving methods, we were able to save $253,773 \mathrm{Kwh}$ during this year.

The company is trying to introduce energy-efficient tools, equipment, and methods for better energy use and as a solution for the scarcity of energy sources.

\section{Accounting for materials}

In addition to accounting for energy, another usage of EMA in the company is accounting for materials. Accounting for materials is specific depending on the industry. (Gunaratne, N \& Alahakoon, Y 2016). We have noted the accounting approaches for materials in this company, such as material analysis as per cost centers, calculating the material cost per unit and analyzing the waste of material usage. As per the Bennet \& James (1997), collection of the data regarding the materials is important to environmental-related management accounting. It helps to get accurate costing outputs and it leads to minimising the waste successfully. The Accountant of the Location 1 factory remarked:

The tile manufacturing process requires the materials like ball clay, kaolin and feldspar. Most of the materials are non-renewable. Since that, we are trying to minimise wastage \& reuse resources. In this tile sector, we were able to recycle and use $99 \%$ of the minerals. The balance materials were crushed and used to refill clay mines.

As per the explanations of the Head of the production at Location 2 factory, the company as usage of the gathered costing data the company is using them to the product pricing decisions. In the tile manufacturing sector, certain tiles need special colours and sizes. The production process varies based on the ceramic tiles and porcelain tiles. After the tile is manufactured, the colouring process is different from a bundle of tiles. Those tiles can be damaged during the production process. The company has started to reuse those tiles after cutting the damaged areas. From that, the company is expected to utilize the materials effectively. This is a process where accounting and management for material is driven for efficiency. These explanations are supported by the data collected regarding the material consumption of the company.

\section{Accounting for water}

Another application of EMA that the company is using can be mentioned as Accounting for water. Even though the water resource in Sri Lanka is not rare, the Sri Lankan companies pay more attention to managing the water and accounting for the used water resource. Adjustment of the water properties must be in line with the regulatory requirements before discharge. (Gunarathne, N \& Alahakoon, Y 2016). The Head of production commented, "For tile manufacturing, one of the main inputs is water. We use groundwater, municipal waste, rainwater, and supply from the third party." Wastewater 
treatment accounting is one of the EMA aspects in accounting for water. This company has introduced wastewater treatment plants to treat used water. They collect the Wastewater, treat the water and reuse this recycled water for the production process. Another way of applying accounting for water is calculating the total cost for the water during the period, Total litres of consumed water and Wastewater and calculating the water intensity ratio. The below graph shows that the consumption of water based on the source and the wastewater quantity.

\section{Accounting for garbage}

Accounting for garbage is another area that the company focused. The company has applied $3 \mathrm{R}$ method (Reduce, Reuse, Recycle) for managing garbage generated by the factories. That garbage can be categorized as organic waste and sludge waste. Sludge waste generated from the production process is collected and that waste is the raw material for the cement manufacturing industry. As per the explanations by the Assistant Accountant of Location 1 factory, the way of applying to account for garbage is calculating the profit-generating from the sludge waste selling to cement manufacturing. They calculate the cost for sludge waste and related cost of sales during the period of one month, get the selling price, and calculate the profit. Another usage of EMA is calculating the sludge intensity ratio from a total of sludge waste and sold sludge waste. The use of sludge waste is supported by the comments below from the Accountant of the Location 1 factory.

As accounting for garbage, we mainly focus on the accounting for sludge waste. Sludge waste means the waste generated from the production process of tiles. Sludge waste is one of the main inputs of the cement manufacturing process. So, we are selling them to cement manufacturing companies. We are getting income from that. Moreover, we identify that income as other income in our accounts.

The company has a plan to minimise electricity consumption and use a solar power system for the production process. Further, they hope to minimise the effect on the environment from the mining activities of clay lands. The world-recognized guideline for environmental reporting is provided by the Global Reporting Initiative (GRI). GRI has developed a sustainability reporting framework and it is widely used around the world. GRI framework enables organisations to measure \& report sustainability under the economic, social, environmental \& governance.

Today, most of the companies in Sri Lanka are using GRI guidelines when publishing their annual reports. The environmental guideline concerns the living and non-living natural systems. Under that, they consider the environmental input indicators such as material, energy, and water. In the Annual reports of $\mathrm{ABC}$, they have disclosed their information as per the GRI standards. In relation to the materials (GRI 301-1 material used by weight or volume, GRI 301-2 recycled input materials used), Energy (GRI 302-1 energy consumption within the organization, GRI 302-4 Reduction of energy consumption), Water (GRI 303-1 Water withdrawal by source, GRI 303-3 Water recycled \& reused), Effluents \& Waste (GRI 306-1 Water discharge by quality \& destination, GRI 306-2 Waste by type \& disposal method) in the company annual reports they have disclosure details.

As per the research study done by Aruppola \& Perera (2013), the average disclosure rate of environmental practices is significantly low. In that research, they have indicated that the disclosure rate of environmental accounting is relatively high in the $\mathrm{ABC}$ group. The waste management practices for EMA discussed above have been able to utilize the environmental resources used by the company. The next part of the findings presents the motivations to apply EMA practices for waste management within the company.

\section{Motivations to implement Waste Management \& EMA practices}

Since the company has implemented waste management practices related to EMA practices, it is important to identify the guiding factors to adopt them. In this part of the study, the influencing factors are discussed based on the theoretical insights drawn from the institutional theory. Therefore, the diverse influences for waste management are discussed under three pillars: Coercive isomorphism, mimetic isomorphism, and normative isomorphism. 
Coercive isomorphism can be occurred because of the imposed rules and regulations of the country, which are relevant to the manufacturing companies. The company implements waste management \& EMA practices mainly due to the pressure exerted by the government. The Accountant of the Location 1 factory commented:

As per the National environmental act, we must obtain an environmental protection license. In that there are schemes for wastewater discharge, noise control regulations and vibration controls. And there are gazettes regarding wastewater disposal. We have obtained those licenses and we discharge our Wastewater according to them without harming internal surface water.

The Accountant of the Location 2 factory supported the Accountant of Location 1 by commenting: "Under the environmental act in Sri Lanka, there are regulations for the management of waste, limitations of the industrial waste, limits for the discharge of industrial waste to inland surface water and regulations for solid waste........ According to the Accountants, when they apply for the license, they must disclose their reusing process, recycling process, waste categories, waste storing methods, time that such things are storing and so many other details they are checked in the process of giving the license. As a leading tile manufacturing company, $\mathrm{ABC}$ company has fulfilled all those criteria and obtained the license regarding ensuring environmental protection.

According to Qian \& Burritt in 2009, coercive pressure forces the organization to comply with rules, schemes, and inferential sets. Being a leading and well-known tile manufacturer in Sri Lanka, ABC must comply with the rules \& regulations granted by the environmental authorities. As per the above explanations, the company engages with environmental compliance because of the rules and regulations. Since that this practice of ABC company has been consistent with coercive isomorphism.

Mimetic isomorphism also becomes evident in relation to the adoption of certain practices. In certain instances, due to some inherent limitations of the company, it may tend to follow certain actions of others. As ABC is the main player in the tile manufacturing sector in Sri Lanka, the company has no other role models in the same industry. However, the company has followed certain actions taken by other companies in other sectors and the world's best companies operate overseas. It was confirmed by the Accountant of Location 1 factory saying that;

Since we are the leading tile manufacturer in Sri Lanka, we do not have role models in the tile manufacturing sector. But from our risk analyzing teams analyze the risk associated with them. The world's best tile manufacturing country is China. Second one is India. Kajaria, Somany, Nitco and simpola are the best brand for tiles in the world market. In concern of environmental awareness and the impact to the environment is very low in their production process, they are using the latest technology \& day by day they are updating with new sustainable techniques.

As per the Accountant's comments, they have the objective to be par with other world best tile manufacturers. Thus, they intend to update their technology like the main suppliers in the world tile industry. As those companies use sustainable environmental concepts and techniques, the company is also willing to use them within their capacity. Moreover, mimetic isomorphism is further evident when $\mathrm{ABC}$ considers how world best tile manufacturers use waste management systems in a better way than $\mathrm{ABC}$ according to their capacity and updated technology. According to the Accountant of Location 2 factory, "In Kajaria ceramics they have installed effluent treatment plant to filter liquid and solid waste. From the same machine, they are recycling and get the waste for reuse. Recent company reports show that they have been able to reduce their waste generation to 5\% less than from their total production." As per the factory accountants' explanations, they want to achieve the best performers in EMA sector in the world tile manufacturing sector. They want to improve their current managing \& reporting practices to obtain the benefits that those companies are getting.

Although the coercive and mimetic pressures make the ABC adopt waste management practices, normative pressures are not clearly given. This is primarily supported by the norms and values of various organisations such as industry trade associations and consulting firms. These norms and 
models are "morally governed" and adopted by social players. Hiring employees from the same industry, Common promotion practices and common skill-level requirements for relevant job roles can results in normative isomorphism. As per the DiMaggio and Powell (1983) there can be two major points of Normative isomorphism. Those sources are cultural expectations and because of interprofessional communication. The Accountant of the Location 1 factory commented how the community likes to see improvements in ABC company's waste management and EMA practices. They are always aware of what the company does in coastal areas. Further, he explained that they are required to provide feedback to people regarding what company engaged in the coastal area and also want to know ABC company's recycling process reuse system etc. Accountant of the Location 1 factory mentioned:

Waste management is the main community service expected by society. Most people like to see improvements in waste management and EMA practices. Our mining sites are located in coastal areas. Also, this factory and Location 2 factory are also situated in coastal areas. People appreciate the natural environment. They like to protect the environment and their expectation is to be protected from us alsoThey want to what happens to their natural water streams and regarding the air pollution especially.

The above explanations were supported by the Accountant at the Location 2 factory as well. He commented that as society has more concern regarding the environment and the company waste managing practices, for the benefit and for the advancement of the company, they wanted to comply with the values and norms of the society-inter-professional communication in the design of accounting information and system that depend on decision-makers perception. Suppose a company gets help from the experts to develop a waste management system that depends on their values and norms. The Assistant Accountant of Location 2 commented:

Since we are not the experts in developing waste management systems and EMA practices, we need the knowledge of the experts in that field. Therefore, we outsource those to a well-known firm. They are analyzing our production systems and giving the best ideas for the company. Also, we started a research program with university students on reducing waste.

The Accountant of the Location 2 factory further supported these explanations. As he stated, they have commenced a program with the support of universities to mitigate the climate-changing key risk. Further, in the future, they have an intention to introduce more waste management practices and EMA techniques. Since the company uses professionals' knowledge in waste management \& introducing EMA practices, those are developed based on their norms \& values. The consulting firms primarily support these norms \& values since there is a normative isomorphism in adopting these practices.

\section{Conclusion}

The main aim of this section is to present the key conclusions of the study. We deployed the case study method to examine the EMA and waste management practices of the company. The case study leads to examine the levels and practices of waste management and EMA practices in the company and motivations to implement these practices. Based on the objectives of the study, the findings are presented as follows.

Current waste management practices, EMA practices, and waste composition of the factory were explored and analyzed in the first part of the study. Since the group of companies is operating under one management, the practices of those premises look similar. Data gathered from interviews, observations and available secondary sources evident that the company's waste management practice on the composition of waste and major part of the waste is generated from the production of tiles. Paper, squaring, food, and organic waste are the other waste items generated in the factory premises.

The Waste Management Hierarchy developed by El- Haggar (2007) is very evident in the actual waste management practice in each context of ABC company. This hierarchy illustrates five significant steps to manage the waste of a company. Accordingly, it is concluded that the company has 
implemented waste management practices under the given hierarchy. Therefore, $A B C$ employs Reduce, Reuse, Recycle, Recover \& Disposal methods under waste management techniques successfully in the company. It is concluded that based on the nature of the waste items identified, $\mathrm{ABC}$ uses suitable methods for managing them. Examine the quality of the production inputs is the major method used to reduce the waste at the initial point. Since the company is more towards the usage of natural resources, they have the issue of scarcity of resources. Therefore, as a solution for the scarcity, the method of reusing is applied in the company factories. While the main treatment for Wastewater is recycling at the factories, the group has invested huge money in September 2019 and installed a separate plant for heat recovery. As the method indicates positive impact, the management is in the idea of introducing that system into other factories as well with great success. Disposing of the waste properly is another method that the company uses a method of waste management. The company introduces the policy of disposing the waste to reduce or eliminate the harmful effect on the environment. Thus, the company maintains rigorous environmental policies in order to ensure the safe disposing of their waste. Further, as per the findings, it is concluded that the company engaged in Accounting for Energy, Accounting for Material, Accounting for Water and Accounting for Garbage as the several areas of Environmental Accounting.

Under the social perspective of institutional theory, the organisations are considered social actors and organisations follow certain practices because of the diverse motivations they underwent in adopting such pracices. Gunarathne \& Lee (2014) suggested that Institutional theory can be used to explain the company's underlying motivations to adopt EMA to be practiced in the accounting systems within the organizational context. This study discusses the motivations under the three pillars: coercive isomorphism, mimetic isomorphism, and normative isomorphism. Firstly, according to the coercive isomorphism, the company operates the waste management techniques because of the rules and regulations imposed by the government, mainly by the Environmental Authority of Sri Lanka. The company considers the world's best tile manufacturing company its role model and introduces its automated, modernized practices to the Sri Lankan context. It can be considered as mimetic isomorphism. Since the company's waste managing activities and new EMA practices are implemented under separate specialized bodies, those systems are created adhering to company values and norms. Moreover, the procedures of waste management are governed by cultural influences. Thus such influences are considered normative isomorphism.

\section{Limitation and study forward}

This study has only focused on the waste management and EMA practices of the one production company in Sri Lanka, called ABC Ceramics PLC and its factories situated in Location 1 and Location 2 to gather information. As there are other leading tile manufacturers in Sri Lanka, it will be more successful if it could execute the research by comparing the waste management practices and EMA practices of those similar companies. This study is focused only on the one main ceramic production company operating in Sri Lanka. Thus the waste management practices of other production companies are important to be explored. The study is done using the case study method and the results are unable to be generalized. Studying and providing conclusions for a single organization without considering the industry or similar organisations can be considered as a limitation of the case study method. Further, restrictions in accessing the company's information due to confidentiality created a detrimental impact on the research work.

The research has identified the current practices and causes for those practices in one of the organisations in the manufacturing sector. However, future research can be conducted on the other companies which operate in diverse sectors in different local and international contexts. Future research can be conducted to examine how Environmental Management Accounting is positioned in a company's corporate strategy and the impact of cleaner production practices on Environmental Management Accounting in diverse production companies. 


\section{References}

Aruppola, A., \& Perera, P. (2013). Environmental reporting practice of listed companies in Sri Lanka: Evidence from Manufacturing, Motor, Power and Energy Sectors. In International Conference on Business and Information. 1st to 2nd November.

Australian Ecologically Sustainable Development Steering Committee 1992, viewed on 10 January 2020, http://www.environment.gov. au/ esd/national/nsesd/strategy/wastes.html

DiMaggio, P. J., \& Powell, W.W. (1983). The iron cage revisited: Institutional isomorphism and collective rationality in organizational fields. American Sociological Review, 48(2), 60-147.

El-Haggar. (2007). Sustainable industrial design and waste management: Cradle-to-cradle. Elsevier Academic Press: An International Journal.

Gunarathne, N., \& Alahakoon, Y. (2016). Environmental management accounting practices and their diffusion: The Sri Lankan Experience. NSBM Journal of Management, 1-26.

Gunarathne, N., \& Lee, K. H. (2015). Environmental Management Accounting (EMA) for environmental management and organizational change. Journal of Accounting \& Organizational Change, 11(3), 362-383.

Gunarathne, N., \& Lee, K. H. (2014). Fostering environmental management practices with supporting tools of sustainability accounting: an institutional theory. Journal of Accounting \& Organizational Change.

Gunarathne, N., \& Lee, K. H. (2013). Adopting and implementing environmental Management Accounting practices in the hotel sector: A Sri Lankan case. Journal of Accounting \& Organizational Change.

Hwang, B. G., \& Yeo, Z. B. (2011). Perception on benefits of construction waste management in the Singapore construction industry. Engineering, Construction and Architectural Management, 18(4), 394-406.

National Environmental Act 1980, viewed on 10 January 2020, http://www.cea.lk

Qian, W., Burritt, R., \& Monroe, G. (2009). Environmental management accounting in local government: A case of waste management. Accounting, Auditing \& Accountability Journal, 24(1), 93-128.

Scott, W. R., \& Meyer, J. W. (1995). Institutional analysis: variance and process theory approaches Institutional Environments and Organisations: Structural Complexity and Individualism. Sage, Thousand Oaks, pp. 81-99.

Watchaneeporn, S. (2010). Barriers to the development of environmental management accounting: An exploratory study of pulp and paper companies in Thailand. Euro Med Journal of Business. 